\title{
Blockchain Technology and the Future Development of Cities
}

\author{
Zhang Zhida \\ School of Economics, University of Chinese Academy of Social Sciences, Beijing, China \\ zhangzhida@ucass.edu.cn
}

\begin{abstract}
Judging from the facts of urban development, I believe that technology is the core element that affects urban development and can promote the continuous evolution of urban development. In recent years, blockchain technology has gradually emerged, and is known as the next generation of disruptive core technology following steam engines, electricity, and the Internet. Therefore, the combination of blockchain technology and the future development of cities is an inevitable trend. With its decentralized, open and transparent, non-tamperable, and smart contract characteristics, it will build a global information chain, establish ownership of property rights, and reduce interaction costs. Institutional innovation and other aspects reflect the impact on the future development of the city, which will bring certain changes to the population, activities, and space of the future development of the city, and it will enter the stage of blockchain city in the future. This article will discuss blockchain technology and future urban development, and will verify the feasibility of blockchain cities.
\end{abstract}

Keywords: Blockchain Technology, Blockchain City, Future Development of the City

\section{The Facts of Urban Development}

Judging from the facts of urban development, urban development has successively experienced the agricultural city (5000 to $1750 \mathrm{BC}$ ), the industrial city stage (1750 to 2008), and the smart city stage (after 2008 to present). In these three stages of urban development, the promotion of a core element is particularly important: technology. The industrial revolution represented by steam technology in the 18th century promoted the rise and development of industrial cities, leading to changes in population distribution and changes in lifestyles (Zhuang Jieyou, 1985). The Internet technology produced in the 21 st century has not only brought about the modernization of things, and caused changes in labor methods and lifestyles, but also with the invention and application of cloud computing, Internet of Things, big data and other technologies, it has also created new production methods and industries. Changes in business formats, business models, and management models have brought our city into a smart stage (Jin Yuanpu, 2014).

It is not difficult to see that steam technology has brought us from the agricultural city stage to the industrial city stage, and Internet technology has brought us from the industrial city stage to the smart city stage. Therefore, technology is the core element to promote urban development and will cause changes in the urban development stage.

\section{Overview and Problems of Smart City Development}

We are currently in the stage of smart cities. The concept of smart cities was first proposed by IBM in November 2008. The first official mention of smart cities in China was the State Council's "Issuance of the Industrial Transformation and Upgrading Plan (2011-2015)" issued in January 2012. ) announcement of". In March 2014, the State Council issued the "National New Urbanization Plan (20142020)", which introduced smart city construction into the national strategic plan for the first time, and proposed that by 2020, a number of distinctive smart cities will be built.

However, there are still a series of problems in smart cities. The first is the phenomenon of "information islands". Although a large amount of basic data is collected, there are gaps in the analysis and integration of data between different departments. The independent construction of each system and the division of blocks, the lack of an effective information sharing mechanism, is not conducive to the sharing of information And to realize the positive externality of information. On the other hand, smart 
cities cannot meet the changes in people's needs, and the needs of modern residents to participate in urban governance have increased significantly. However, the traditional centralized management model cannot realize the multi-participation of residents, causing certain social contradictions.

In recent years, blockchain technology has emerged. It will combine artificial intelligence, big data, $5 \mathrm{G}$ and other Internet technologies to help solve the current problems of smart cities, and build a global information chain on the basis of smart cities. , Establishing the ownership of property rights, reducing interaction costs, institutional innovation and other aspects reflect the impact on the future development of the city, which makes us enter the stage of blockchain city.

\section{Blockchain Technology And Its Characteristics}

\subsection{Blockchain technology}

Blockchain technology is a technology for sharing data between different nodes, allowing us to exchange data without the control of a central database (Glaser, 2017; Risius \& Spohrer, 2017). Blockchain technology originated in the field of digital currency, Bitcoin, and first appeared in "Bitcoin: A Peer-to-Peer Electronic Cash System" (Nakamoto, 2008), but after decades of development, blockchain technology has become more than just Applied to Bitcoin, but with its decentralization, open and transparent, non-tamperable, and smart contract characteristics, it is gradually applied in more fields and more closely integrated with our lives.

\subsection{Characteristics of blockchain technology}

(1) Decentralization. The essence of blockchain technology is a distributed database, which does not rely on a central database, so there is no central control. Each distributed database is called a node. In the blockchain, each person participates in the production, management, and transaction of data as a node on the database. Compared with traditional centralized databases, it is decentralized. feature.

(2) Open and transparent. In addition to the encrypted private data of node transactions, other data of the blockchain is open to all nodes. Any node can query the data in the blockchain through a specific interface, so the entire blockchain is open and transparent.

(3) Cannot be tampered with. Once the data between the different nodes of the blockchain is generated, it will be stored on all nodes. If you want to change a certain data, you need to ensure that the data of all nodes are changed. However, this is difficult to achieve in reality, so it is immutable. Features.

(4) Smart contract. A smart contract is a computer program that is automatically executed in accordance with pre-made rules. As long as the preset conditions are met, the contract will be triggered to establish a relationship of rights and obligations between nodes and execute automatically.

\section{The Future Development of The City}

On October 24, 2019, the Politburo of the Central Committee conducted a collective study on blockchain technology and clearly proposed to use blockchain as the core technology to accelerate the development of blockchain technology. This indicates that blockchain technology has officially become the development of China. Important strategy. Starting from the overall situation of the future development of the city, the author believes that blockchain technology, with its characteristics of decentralization, openness and transparency, non-tamperability, and smart contracts, can help build a global information chain and establish property ownership through information sharing and trust building. , Reducing interaction costs, institutional innovation, etc., thereby affecting the development of future cities, making the city enter the blockchain stage, and verifying the feasibility in the fifth part.

\subsection{Building a global information chain}

In the current society, there are important central institutions such as governments, companies, and banks. They each undertake important functions such as providing public services, commercial transactions, and controlling currency. They control almost all the resources involved in the society, which will cause Inequality, unfairness, opacity and other issues, therefore, it is very necessary to achieve direct contact between members of society. The emergence of blockchain technology will help build a global information chain and make direct contact between members of society possible. 
Blockchain can connect all data blocks in chronological order to form a decentralized information chain. Therefore, blockchain technology enables the construction of a global information chain to be realized, which in turn can break information barriers and realize information The sharing of information better reflects the positive externalities brought about by information sharing. Based on the decentralization, openness and transparency of blockchain technology, each node of the blockchain can participate in the construction of the global information chain, add its own information to the block, and check the information of other nodes at any time. Share information. Information sharing can be carried out between different departments within a city, and information can also be shared between different cities, breaking the phenomenon of information islands, realizing cross-departmental, cross-city, and global data sharing, so that people in future cities can use information more conveniently. Activities such as production, exchange, and consumption.

\subsection{Establish ownership}

Blockchain requires each node to record in a distributed database when making a transaction. Whenever a transaction occurs, the information will be notified to all nodes, and each node will perform the transaction in accordance with preset rules (smart contracts) Confirmation, the information is transparent and unified throughout the process, and the result of confirmation by most nodes is the final consensus. In this way, the property rights of the subject matter of the transaction are clearly fixed, avoiding the occurrence of repeated transactions, and then solving the problem that the ownership is often difficult to judge in modern cities.

\subsection{Reduce interaction costs}

Under the framework of the modern market economy, the division of labor is universal, which leads to the inevitable interaction between people. However, a series of costs (negotiation costs, time costs, money costs, default costs, etc.) are incurred during interaction. The existence of costs leads to a decrease in marginal revenue and limits the interaction between people. The existence of smart contracts in the blockchain can effectively improve interaction efficiency and reduce interaction costs. This is because smart contracts have the characteristics of self-verification and automatic execution.

On the blockchain, transactions between nodes are conducted directly point-to-point through smart contracts. As long as the trigger conditions of the contract are met, the nodes will establish a contract relationship, eliminating the existence of intermediaries, so that people can not only interact directly, but also Save the time of negotiation between the interactive parties. On the other hand, once the contract is signed, the rights and obligations stipulated by the smart contract will be automatically executed, the content cannot be changed, the interests of the interacting parties are guaranteed, the occurrence of defaults after the interaction is reduced, and the interaction cost is reduced.

\subsection{System Innovation}

First of all, the development of blockchain technology needs the support of national and local policies. Secondly, the impact of blockchain technology will be multifaceted and deep-seated, and it will bring huge challenges to the system of the entire society. Since the development of blockchain technology will produce a vacuum zone of laws and regulations, in order to maintain the order in various interactive processes, the emergence of blockchain technology will bring about the innovation of social systems, and the blockchain will affect organizations. The management rules, urban information sharing rules, and social legal systems have more and more influence.

After the above analysis of future urban development, the future blockchain city can be summarized from three aspects: population, urban activities, and urban space. (1) Population. In the future, the structure of the urban population will be residents + public sector. Residents participate in the management of urban society in a decentralized manner. The cost of interaction between people is reduced. The existence of smart contracts makes the interaction process more convenient. The determination of property ownership makes interaction The process is more scientific. So as to form a system of population global connections. (2) Urban activities. The content of future urban activities will be the production, combination and consumption of information, and the growth rate of information will be rapid, forming a global information chain, almost all global urban activities will be included in the blockchain, this is due to modern cities Development is determined by the increasing frequency of interaction. On the other hand, due to the impact of blockchain technology on modern social systems, urban activities will also include many institutional innovations. (3) Urban space. The urban space in the 
future will be block-style, and there will be no continued settlement of residents, because at this stage, smart cities have already experienced urban diseases, which affects the increasing return to scale. The emergence of blockchain technology makes people no longer need to have higher returns. The driving force of living in the government, banks, enterprises and other important central institutions, the future management model is decentralized, without the existence of too many central management institutions.

\section{Feasibility Verification}

According to the relevant data in the "2018 China Blockchain Industry White Paper" published by the Information Center of the Ministry of Industry and Information Technology of China, the following will be from the three aspects of the number of blockchain companies, the blockchain policy system, and the training of blockchain talents. Verify the feasibility of the city entering the blockchain stage.

\subsection{The number of blockchain technology companies is increasing rapidly}

As of the end of 2017, the number of China's blockchain companies based on blockchain technology has reached 434, initially forming a certain scale. Judging from the increase in the number of newly established blockchain technology companies in China, the number of related companies has increased since 2014, and the number of newly established companies has increased significantly in 2016, exceeding 100, which is nearly five in 2013. Times. 2017 is the peak of blockchain technology entrepreneurship in recent years. As more and more blockchain technology has entered people's sights, relevant blockchain technology talents have entered it, and the number of newly established companies has reached 178. It is expected that the future The number of blockchain companies will continue to increase rapidly in a few years.

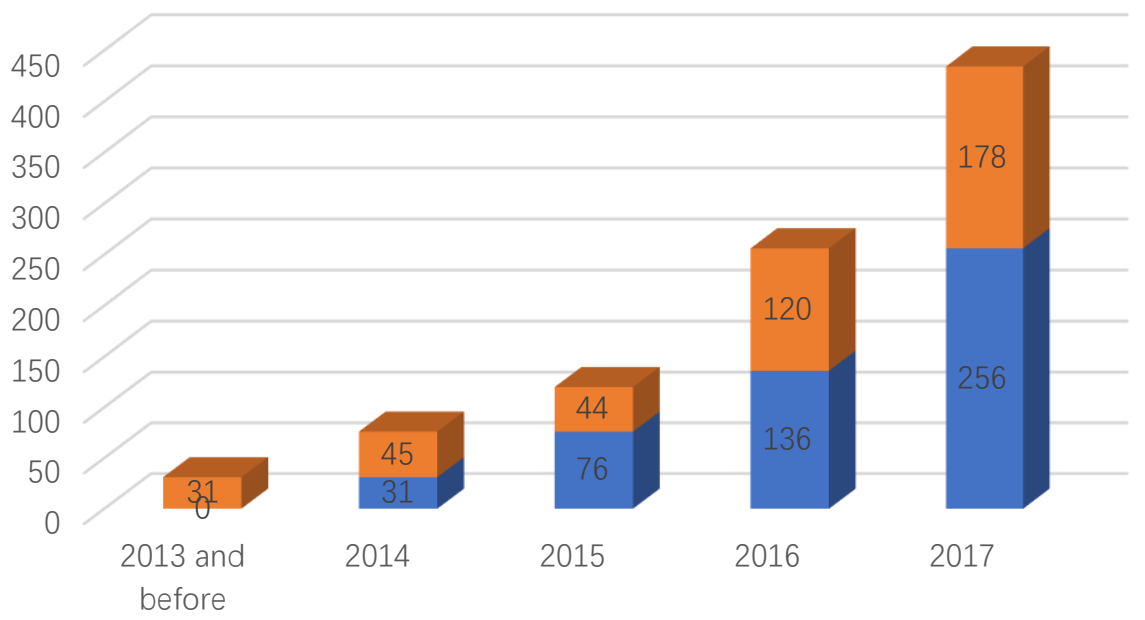

- Number of Companies in the previous year $n$ Number of new companies this year

Figure 1 The number of newly established companies in China's blockchain industry in recent years

Table 1 Top 10 cities for China's blockchain entrepreneurial activity

\begin{tabular}{|c|c|c|c|}
\hline Ranking & City & Number of Companies & Proportion \\
\hline 1 & Beijing & 175 & $38 \%$ \\
\hline 2 & Shanghai & 95 & $21 \%$ \\
\hline 3 & Shenzhen & 56 & $12 \%$ \\
\hline 4 & Hangzhou & 32 & $7 \%$ \\
\hline 5 & Guangzhou & 15 & $3 \%$ \\
\hline 6 & Chengdu & 13 & $3 \%$ \\
\hline 7 & Nanjing & 8 & $2 \%$ \\
\hline 8 & Xiamen & 4 & $1 \%$ \\
\hline 9 & Chongqing & 4 & $1 \%$ \\
\hline 10 & Guiyang & 3 & $1 \%$ \\
\hline
\end{tabular}


From the perspective of the distribution of China's blockchain companies, Beijing, Shanghai, and Shenzhen are the concentrated locations for blockchain entrepreneurship, accounting for more than $70 \%$ of the total. Among them, Beijing has an absolute leading position with 175 startup companies. From this point of view, it may be the first to enter the blockchain city in the future.

\subsection{Continuous improvement of the blockchain policy system}

At present, blockchain technology has risen to the level of national science and technology strategy. In 2016, China's "13th Five-Year" national informatization plan clearly stated that the innovation, experimentation and application of new technologies such as blockchain should be strengthened to seize the leadership of the new generation of technology. Moreover, the State Council, the Ministry of Industry and Information Technology, and the State Intellectual Property State ministries and commissions such as the Bureau and the Ministry of Education have also formulated relevant policies. On the other hand, in order to grasp the development opportunities of the blockchain industry, the governments of Shanghai, Beijing, Hangzhou and other localities have gradually introduced more policies, making the policy system related to blockchain technology continuous improvement and bringing institutional innovations.

Table 2 National policies related to blockchain technology (partial)

\begin{tabular}{|c|c|c|}
\hline Issue date & File name & Issuer \\
\hline December 2016 & $\begin{array}{l}\text { "The 13th Five-Year Plan for National } \\
\text { Informatization" }\end{array}$ & State Council \\
\hline December 2016 & $\begin{array}{l}\text { "Software and Information Technology Service } \\
\text { Industry Development Plan (2016-2020)" }\end{array}$ & $\begin{array}{l}\text { Ministry of Industry and } \\
\text { Information Technology }\end{array}$ \\
\hline March 2017 & $\begin{array}{l}\text { "Three-year Action Plan for Cloud Computing } \\
\text { Development (2017-2019)" }\end{array}$ & $\begin{array}{l}\text { Ministry of Industry and } \\
\text { Information Technology }\end{array}$ \\
\hline July 2017 & $\begin{array}{l}\text { "New Generation Artificial Intelligence } \\
\text { Development Plan" }\end{array}$ & State Council \\
\hline January 2018 & $\begin{array}{l}\text { "Catalogue of Key Intellectual Property } \\
\text { Support Industries (2018 Edition)" }\end{array}$ & $\begin{array}{l}\text { State Intellectual } \\
\text { Property Office }\end{array}$ \\
\hline April 2018 & $\begin{array}{l}\text { "Education Informationization } 2.0 \text { Action } \\
\text { Plan" }\end{array}$ & Ministry of Education \\
\hline
\end{tabular}

Table 3 Local policies related to the blockchain industry (partial)

\begin{tabular}{|c|c|c|}
\hline Issue date & File name & Issuer \\
\hline June 2017 & $\begin{array}{l}\text { "Xuhui District Key Development Industry } \\
\text { Guidance Catalog (2017 Edition)" }\end{array}$ & $\begin{array}{l}\text { People's Government of } \\
\text { Xuhui District, Shanghai }\end{array}$ \\
\hline June 2017 & $\begin{array}{l}\text { "Several Policy Measures to Support the } \\
\text { Development and Application of Blockchain" }\end{array}$ & $\begin{array}{c}\text { General Office of the } \\
\text { People's Government of } \\
\text { Guiyang City }\end{array}$ \\
\hline September 2017 & $\begin{array}{c}\text { "Opinions on Building Xixi Valley Blockchain } \\
\text { Industrial Park" }\end{array}$ & $\begin{array}{l}\text { Xihu District } \\
\text { Government of } \\
\text { Hangzhou City }\end{array}$ \\
\hline October 2017 & $\begin{array}{l}\text { "'Shijingshan Service" Action Plan (2017- } \\
\text { 2020)" }\end{array}$ & $\begin{array}{l}\text { People's Government of } \\
\text { Shijingshan District, } \\
\text { Beijing }\end{array}$ \\
\hline November 2017 & $\begin{array}{c}\text { "Tianjin City's Implementation Plan for } \\
\text { Further Expansion and Upgrade of Information } \\
\text { Consumption" }\end{array}$ & $\begin{array}{l}\text { Tianjin Municipal } \\
\text { People's Government }\end{array}$ \\
\hline November 2017 & $\begin{array}{c}\text { "Opinions on Accelerating the Cultivation and } \\
\text { Innovative Application of the Blockchain } \\
\text { Industry" }\end{array}$ & $\begin{array}{l}\text { Chongqing Economic } \\
\text { and Information } \\
\text { Technology Commission }\end{array}$ \\
\hline March 2018 & $\begin{array}{l}\text { "Shenzhen's second batch of support plans for } \\
\text { strategic emerging industries in 2018" }\end{array}$ & $\begin{array}{l}\text { Shenzhen Economic, } \\
\text { Trade and Information } \\
\text { Commission }\end{array}$ \\
\hline
\end{tabular}

\subsection{Cultivation of blockchain technology talents}

The application of blockchain technology and the training of talents are inseparable. Therefore, universities in all regions are actively setting up special training centers to provide talents for the 
ISSN 2616-5767 Vol.4, Issue 7: 22-27, DOI: 10.25236/AJETS.2021.040705

development of blockchain technology in China. For example, Tsinghua University iCenter, Zhejiang University Software School, Tongji University Financial Technology Research Institute, Beijing University of Posts and Telecommunications Online Blockchain Education and Research Center, Harbin Institute of Technology and other universities have all opened blockchain-related courses. With the gradual maturity of the training model of blockchain technology talents, it will promote the further development of blockchain technology and help cities enter the blockchain stage.

\section{Conclusion}

From the analysis of this article, it can be concluded that blockchain technology, as an emerging disruptive technology, will promote the future development of cities into the blockchain city stage. Innovation and other aspects reflect the impact on the future development of the city, bring certain changes to the population, activities, and space of the future development of the city, and the feasibility verification has strongly proved the feasibility of entering the blockchain city stage.

\section{References}

[1] Zhuang Jieyou. The economic and social impact of the world's first industrial revolution [J]. Journal of Xiamen University (Philosophy and Social Sciences Edition), 1985(04): 54-60+68.

[2] Jin Yuanpu. Internet thinking: paradigm change in the era of scientific and technological revolution[J]. Fujian Forum (Humanities and Social Sciences Edition), 2014(10): 42-48.

[3] Glaser F. Pervasive decentralisation of digital infrastructures: a framework for blockchain enabled system and use case analysis[J]. 2017.

[4] Risius M, Spohrer K. A blockchain research framework[J]. Business \& Information Systems Engineering, 2017, 59(6): 385-409.

[5] Nakamoto S. Bitcoin: A peer-to-peer electronic cash system[J]. Decentralized Business Review, 2008. 21260 . 